\title{
A Before-After Control-Impact Assessment of Gravel Washing as a Lacustrine Spawning Habitat Restoration Method for Smallmouth Bass (Micropterus dolomieu)
}

\author{
By \\ Daniel M. Glassman \\ B.Sc., Carleton University
}

A thesis submitted to the Faculty of Graduate and Postdoctoral

Affairs in partial fulfillment of the requirements

for the degree of

Master of Science

in

Biology

Carleton University

Ottawa, Ontario

CC2021, Daniel M. Glassman 


\section{Abstract:}

Smallmouth bass (Micropterus dolomieu) spawn on clean sand and gravel in the littoral zone of lakes, which may become degraded by the presence of fine sediments and decomposing organic matter. Substrate size and composition have been identified as important variables for nest site selection by male bass. I tested whether cleaning substrate with a pressure washer to remove smaller sediment would increase the number of bass nests or the average length of bass nesting in an area the following year using a before-after control-impact design. Treatment was not a significant predictor of nest abundance or average male length. Considering the strength of the experimental design it is reasonable to conclude that this intervention is ineffective in lakes for enhancing spawning substrate for bass. Understanding the factors that maintain productive spawning sites for smallmouth bass is important to restoration effectiveness and determine where habitat enhancement will provide a benefit or not. 


\section{Acknowledgements:}

The research presented throughout this thesis was supported by NSERC and the Great Lakes Guardian Community Fund. The Queen's University Biological Station was my home away from home during the fieldwork for this project; the support provided through the use of its facilities, and the friends I made there contributed immeasurably to this work and my development as a researcher. I would like to acknowledge my supervisor, Steven Cooke, whose mentorship and opportunities provided to me have been instrumental to my academic and personal growth. To Lisa Donaldson, without whose good company and work to get this project through the first season this project would not have happened. And to the other Cooke Lab members who braved stormy weather and frigid water alongside me: Auston Chhor, Ben Hlina, Alice Abrams, Jordanna Bergman, Tanya Prystay, Michael Lawrence, Brooke Etherington, and Aline Litt. I would also like to thank my committee members Jesse Vermaire and François for their guidance and support. And to Bill Glassman, Lies Weijs, Cynthia Weijs, Dave Glassman, and Jennifer Cooke, whose patience, support, and belief in me has kept me afloat in trying times. 
Table of Contents:

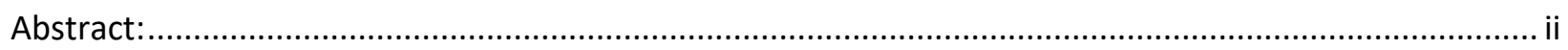

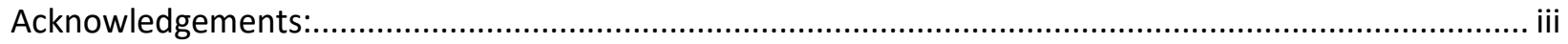

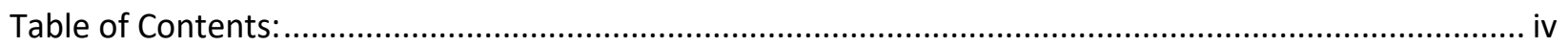

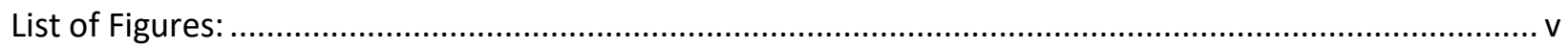

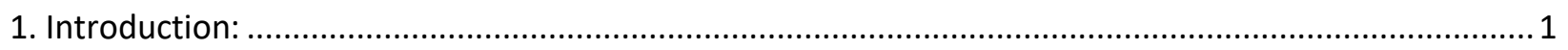

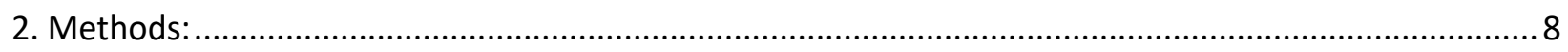

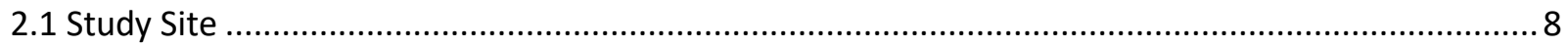

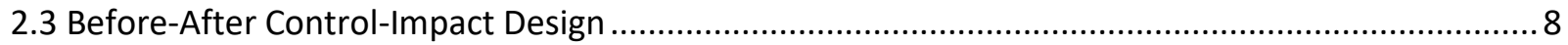

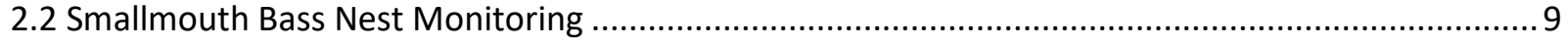

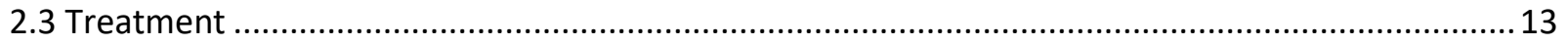

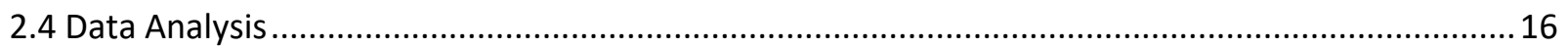

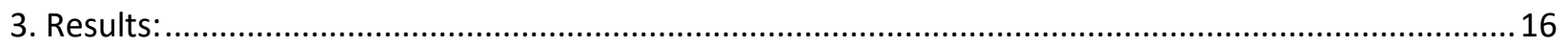

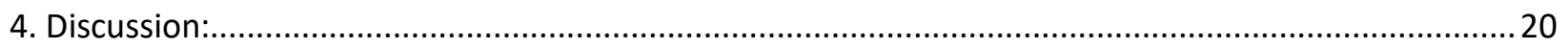

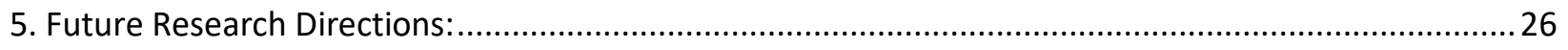

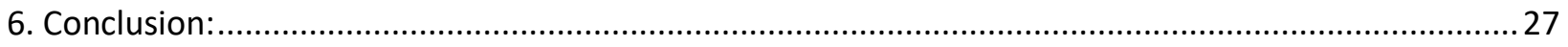

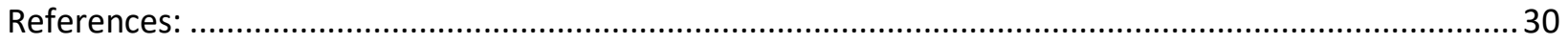




\section{List of Figures:}

Figure 1: Example of shoreline included in the study from Big Island on Big Rideau Lake, with snorkelers surveying for nests. Taken on May 29, 2018 during baseline nest monitoring.

Figure 2: Photo of a smallmouth bass nest with a male guarding and a white PVC nest tag used to avoid double counting nests. The larger gravel and cobble substrate in the nest can be clearly distinguished from the surrounding fine substrate. 1110

Figure 3: Map showing the locations of treatment (green) and control (red) transects on Big Rideau Lake, Ontario. 1211

Figure 4: Picture of the gas-powered pressure washer with operator in the water $(A)$ and operator holding the spraying wand (B). The black attachment above the operator's left hand is an action camera used to record video of the restoration process.

Figure 5: Illustration of the gravel cleaning method used in this study (A). As the cleaning in this study took place in shallow water, a snorkel, rather than SCUBA suit was used (B). A red rope was used to mark the transect and the diver worked along the rope facing away from shore so the sediment plume would travel away from the spawning habitat into deeper water. Figure $2 \mathrm{~A}$ reproduced from Baetz et al. (2020) Review of Methods to Repair and Maintain Lithophilic Fish Spawning Habitat. Water 12:1-37.

Figure 6: Boxplot of the change in nest abundance in control and cleaned spawning habitat transects. The bold horizontal line shows the median change, the upper and lower box hinges show the $75^{\text {th }}$ and $25^{\text {th }}$ percentile, and the whiskers show 1.5 times the interquartile range. Points beyond 1.5 times the interquartile range are shown with black dots.

Figure 7: Violin plot showing distribution of nesting smallmouth bass lengths in control and treatment transects before (white) and after (grey) restoration. The bold horizontal line shows the median fish length, the upper and lower box hinges show the $75^{\text {th }}$ and $25^{\text {th }}$ percentile, and the whiskers show the range of values within 1.5 times the interquartile range. Points beyond 1.5 times the interquartile range are shown with black dots.

Figure 8: Picture taken following substrate cleaning. The left side of the image is the treated area, and the right is untreated. Improvement in substrate quality can be seen through the reduction in biofilm, vegetation and organic sediment which make the untreated side darker, and increased visibility of larger substrates in the treated section. 


\section{Introduction:}

Globally, freshwater ecosystems are under continued and increasing threats from habitat loss and degradation, climate change, pollution, invasive species, and exploitation of species (Reid et al., 2019). In many ways these are not new threats; for centuries humans have transformed freshwater systems and adjacent lands to support settlement, transportation, irrigation, and drinking water among other uses (Carpenter et al., 2011). The current state of freshwater biodiversity is so dire, and the acknowledgement of it so lacking that it has been termed a hidden crisis (Harrison et al., 2018). Tickner et al. (2020) recently developed an emergency action plan intended to address the biodiversity crisis by halting future declines and developing recovery plans. Central to that plan is the need to restore degraded habitats (i.e., ecological restoration; Suding et al., 2015). Such focus is logical given that habitat loss and degradation is regarded as the top threat to freshwater biodiversity globally and is exacerbated through the indirect effects of the other leading threats (Vitousek et al., 1997; WWF, 2016). Reductions in habitat quality and quantity often constrains biological productivity with direct impacts on biodiversity and human wellbeing (Naeem et al., 2009), yet policies intended to protect habitat continue to fall short (Hoekstra et al., 2005).

Ecological restoration is the process of returning the natural range of variability in biodiversity, ecological processes and structures to an ecosystem that has been degraded, damaged, or destroyed. The term restoration encompasses a range of objectives which may guide the design and goals of a project, including reclamation of heavily disturbed sites, rehabilitation of impacted ecosystem functions, and the highest level of "true" restoration of the characteristic species, communities, and structure of the pre-disturbed ecosystem (Van Diggelen et al., 2001). In recognition of the state of habitat loss and degradation at the global scale, the UN has declared 2021-2030 the Decade on Ecosystem Restoration, stating that the positive benefits from restoration investment far outweigh the cost of action (MARN, 2019). While the perceived benefits of ecological restoration may be great, more often than not projects 
lack any monitoring of the response of the ecosystem to restoration actions, impairing our ability to evaluate the benefits of and learn from successful and unsuccessful efforts (Wortley et al., 2013; Cooke et al., 2019). Furthermore, when restoration success is monitored, practitioners often fail to include a relevant control to compare the effect with (Wortley et al., 2013), and due to publication bias our knowledge of restoration failures is limited (Jennions \& Møller, 2002). As a result, the evidence we do have for successful ecological restoration methods is small, and informed decision-making is often limited to replicating previous efforts without understanding the mechanisms of the process and how it may differ in a new environment (Miller \& Hobbs, 2016). Considering the scale of the mission proposed by the UN Decade on Ecological Restoration, it is vital that we adopt principles in future projects which measure their impact and advance our understanding of restoration processes to capitalize on the momentum of the campaign and provide evidence for the value of continued restoration investment. Due to the financial limitations of restoration budgets and the advantage of having public approval to secure funding, projects should consider the socioeconomic benefits of their actions and allow the needs of local communities to guide decision-making. Incorporating local needs in project planning when designing restoration projects should include selection of ecosystem components to target that are facing threats or declines and provide value to the community.

Freshwater biodiversity is comprised of many diverse taxa but given the current state of freshwater fish populations (WWF, 2021) and the many ecosystem services they provide (Lynch et al., 2016), they represent an area of focus for habitat restoration initiatives (e.g., Roni et al., 2002). Fish may use a variety of habitats for different life-history processes including spawning, nursery, and feeding habitats, as well as the connective habitat required to travel between them. Spawning habitat specialists may spend most of their time roaming vast areas in rivers and lakes but rely on only a small area of habitat with suitable conditions for successful reproduction. In recognition of the importance of habitat, laws in many jurisdictions regulate activities which could destroy or alter fish habitat and require 
offsetting of negative impacts through the restoration, enhancement, or creation of new habitat (Poulton, 2015). However, the information available to guide spawning habitat enhancement is limited with many studies having flawed design, and little replication of studies on the same method. Common issues included lacking proper experimental controls, pseudoreplication, and poor matching of control and experimental sites (Rytwinski et al., 2019). Taylor et al. (2019) suggest that the optimal design for spawning habitat restoration studies is a Before-After Control-Impact (BACI) design, with quantitative outcome monitoring, and replication occurring at the scale of intervention.

Smallmouth bass (Micropterus dolomieu) are a species of great importance to the recreational fishing industry in North America, contributing millions if not billions to the economy annually in addition to social and mental health benefits (Tufts et al., 2015). The value of populations to local economies can depend on the size and/or quantity of fish caught as anglers may travel to access better angling opportunities (Post et al., 2002). Although they are widely distributed and abundant, classified as least concern by the IUCN (NatureServe, 2013), smallmouth bass's popularity as a sportfish can impact local populations due to over-exploitation. Despite the best intentions of catch-and-release angling, post-release mortality and sub-lethal effects can have a significant impact on populations (Cooke \& Wilde, 2007). Moreover, because bass spawn in littoral regions they are subject to habitat alteration and loss associated with shoreline development (Jennings et al. 1999). Kaufmann et al. (2014) conducted a nation-wide survey in the United States and revealed that nearshore (littoral) habitats were extensively altered in most lakes and reservoirs, and shoreline development has been shown to correlate with reduced habitat structure and suitability for nesting bass (Lawson et al., 2011). Ensuring sufficient quantity and quality of habitat is available to sustain healthy fish populations is necessary to provide continued access to the benefits of recreational angling in the future (Lapointe et al., 2014).

Studies have shown that smallmouth bass select spawning habitats with substrate sizes ranging from coarse sand or gravel to cobble over fine sand, silt, or clay (Neves, 1975; Bozek et al., 2002). Male 
smallmouth bass prepare a nest for spawning by sweeping debris away with caudal fin-beats. This creates a circular depression with finer sediments removed. A female smallmouth who is successfully courted will deposit adhesive eggs in the center of the cleaned area (Hinch \& Collins, 1991). If the eggs are laid on fine substrates, they will not be strongly anchored and could be washed away from the nest. The male then guards the eggs and ventilates them using pectoral fin movements for several days until hatching (Hinch \& Collins, 1991). In areas with fine, easily suspended substrates water movement may deposit fine sediment on the eggs, which the male must fan to remove the fine sediment and prevent the eggs from being smothered. After eggs hatch the male continues to guard its brood until they are developed enough to live independently. During the parental care period the male drastically reduces feeding, relying primarily on energy reserves (Mackereth et al., 1999) so choosing a nest site that reduces energy expenditure is favourable to their reproductive success. In areas with more fine sediment male bass may have to invest more energy in the initial cleaning of the nest and during the egg development stage to keep the nest clean, so when choosing a nest site they should prefer areas with less fine sediment. The spawning period occurs in the spring following winter, which is a period of low food availability and low activity for smallmouth bass in northern climates. As a result, male bass have to replenish their energy reserves after ice-out before they can begin nesting (Gravel et al., 2010). Larger bass generally have larger energy reserves relative to metabolic rate compared to smaller bass, so they need to spend less time replenishing their energy reserves and can begin nesting earlier in the season (Ridgway et al., 1991b; Ridgeway \& Shuter, 1996). This means that larger bass have more choice of where to nest than smaller bass which spawn later.

A common threat to species with similar spawning habitat requirements to smallmouth bass is the accumulation of fine sediments over their preferred substrate, as this can cause increased egg mortality and abandonment of spawning habitats (Baetz et al., 2020). In lotic systems, studies have 
found jetting or washing substrates has been successful in improving the conditions for substrate spawning fish by reducing fine sediment content near the surface (Meyer et al., 2008; Bašić et al., 2017). However, a recent systematic review of spawning habitat creation and enhancement for substratespawning fish identified that there are not enough high-quality studies, including ones with a beforeafter control-impact (BACl) design, of substrate cleaning to assess the effectiveness of the method, (Taylor et al., 2019). In rivers and lotic environments, disturbed sediment is moved away from the area, increasing the effectiveness of cleaning. In lentic lacustrine environments there is little to no current to move sediment away from the treated area, but there is potentially less transport of sediment into the habitat, so although cleaning may be less effective, the results may persist longer. Studies of spawning substrate cleaning effectiveness are heavily biased towards salmonid species which spawn in rivers (Taylor et al., 2019), so although the method could be beneficial in lacustrine environments there are no studies to evaluate that possibility.

Studies of spawning habitat restoration often measure improvements in habitat variables rather than biological responses such as fish abundance or number of nests. Instead, there is a strong body of evidence which relate the amount of fine sediment or hydraulic conductivity of spawning habitat to salmonid egg survival (Tappel \& Bjornn, 1983; Young et al., 1991; Lapointe et al., 2004). These physical changes in habitat quality may be measured at any time, while spawning occurs only once a year, so they provide a convenient proxy for reproductive success. Early methods of gravel cleaning were labour intensive and often involved operating heavy equipment in the water to disturb the riverbed and allow fine sediment to be carried away, or remove the sediment, mechanically sort out smaller particles and replace it (Mih \& Bailey, 1981). This worked well in artificial spawning sites which were maintained purely for salmonid spawning, but in natural habitats where other species are present the disturbance caused by the equipment to the instream and riparian habitat is undesirable. In testing other gravel washing methods, power washing and pump washing were found to be less invasive and more cost- 
effective to reduce the amount of fine sediment at a site scale than rotovating and physical disturbance (Shackle et al., 1999). Others have also reported that jetting or washing substrates has been successful in improving the conditions for substrate spawning fish by reducing the proportion of fine sediment near the surface (Meyer et al., 2008; Bašić et al., 2017). Due to the issues of poor study design and low replication, as well as the paucity of studies which measure biological responses, there is insufficient information to conclude whether gravel washing is an effective intervention.

Bass are expected to choose habitat that is optimal for egg survival, and requires the least amount of energy investment to prepare and maintain a nest in. Habitat with less fine sediment and organic debris will require less time to prepare a nest in and provide better conditions for egg development, as organic debris reduces dissolved oxygen as it decomposes and fine sediment restricts water circulation around the eggs, also contributing to hypoxia (Lukas \& Orth, 1995; Lapointe et al., 2004; Dauwalter \& Fisher, 2007). If the gravel and cobble cleaning is successful at reducing fine sediment and organic debris, it would be expected that bass would select that habitat over uncleaned gravel and cobble. This could result in increased numbers of bass nesting in an area, however bass nest site selection is also density-dependant (DeAngelis et al., 1991), so there could be a limit on the number of nests and area would support regardless of its quality. If that is the case, then improvements in habitat quality could lead to better habitat being selected by larger (older) bass that tend to have higher reproductive success (Raffetto et al., 1990; Wiegmann \& Baylis, 1995; Gingerich \& Suski, 2011). Larger bass are known to spawn earlier in the season, possibly due to having larger energy stores which allow them to spend a longer time preparing a nest and providing parental care (Ridgway et al., 1991b; Wiegmann \& Baylis, 1995). Therefore, if a change in nest abundance is not seen in restored areas, an increase in the size of fish using sites could indicate an improvement in substrate quality.

As there is no existing literature on efforts to clean fish spawning substrate in non-moving water, and no literature on substrate cleaning for smallmouth bass, I took the opportunity to test this 
method in a novel environment. I hypothesized that cleaning spawning substrate would increase the number of smallmouth bass spawning in an area because cleaning would improve the conditions for smallmouth bass nest building and egg development, so to minimize energy expenditure and improve their reproductive success bass would nest in cleaned areas over uncleaned areas. My second hypothesis was that average male bass size would increase in areas after cleaning because larger bass which can spawn earlier would select the highest quality habitat with smaller bass nesting in the remaining lower-quality habitat when they arrive. To ensure my results embodied the highest level of quality evidence, I chose a replicated before-after control-impact (BACl) design, to test these hypotheses. $\mathrm{BACl}$ designs are considered to be an optimal study design in environmental effects monitoring because they allow researchers to measure the impact of an event while controlling for the effects of unrelated changes or processes over the same period. By including a control which is like the treated area and influenced by the same factors as the treated area, the true effect of the treatment can be measured as the relative difference in change within the treatment areas compared to the control areas (Smith, 2014). Another important factor to consider is the natural variability of ecological systems; populations exhibit dynamic changes over time due to predator-prey interactions, conspecific and interspecific competition, and random events (Conquest, 2000). Using only a single treatment or control area runs the risk of mistaking natural variability in the system for an effect, and sometimes this is unavoidable due to the nature of the event being measured (e.g. construction of a dam on a river), in which case careful statistical analysis and replicate measurements in time should be used to minimize the effect of sampling error (Smokorowski \& Randall, 2017). By measuring the change in multiple treatment and control locations, the distribution of responses can be used to estimate the true effect as well as the natural variation in the sampled areas, although measuring an effect in a species with large natural variability may be difficult because the noise of the random effects can overwhelm the true effect's signal (Underwood, 1992). The goal of this study was to generate knowledge to guide efforts in 
smallmouth bass spawning habitat restoration in lacustrine environments and provide an example of effective project design and monitoring that can benefit future restoration projects in freshwater habitat restoration.

\section{Methods:}

\subsection{Study Site}

The study took place on Big Rideau Lake, a 4700 ha meso-oligotrophic lake in southeastern Ontario, Canada. The lake is part of the Rideau Waterway, an historic waterway used for recreation and travel. The shoreline is a mixture of cottages and undeveloped land and is a popular destination for anglers, with multiple bass fishing tournaments hosted on the lake every year. Using knowledge from researchers who had previously studied nesting smallmouth bass on the lake, I identified several shorelines which contained good potential nesting habitat and had been used for spawning in the past. I also identified shorelines that could support spawning but were not known to be used previously. Habitat was considered suitable for spawning if the predominant grain size of the substrate ranged from sand to cobble, with a low slope, and negligible macrophyte growth in 0-3 m depth range (Bozek et al., 2002).

\subsection{Before-After Control-Impact Design}

To compare the effect of cleaning the substrate we used a BACl experimental design. The essence of this is comparing the change of the measured variables before and after the impact (cleaning) within the impacted areas and closely related areas which were not impacted by the cleaning. This provides two categorical predictor variables with two levels each: year (2018 and 2019) and treatment (treatment and control). The reason for including control sites is to provide a reference to the impact site which experiences similar environmental conditions such as weather during the spawning season or lake-wide water quality changes which could impact the number of spawning bass in a season. 
Baseline monitoring of smallmouth spawning use took place in spring 2018. Surveys began after surface water temperatures in the areas to be observed reached $15^{\circ} \mathrm{C}$, the threshold for smallmouth bass spawning to begin. Each shoreline was surveyed twice each year, one week apart to capture the use of the site over the course of the spawning period. After the baseline monitoring and mapping of the nests, the shorelines were divided into $50 \mathrm{~m}$ transects and assigned in pairs as treatment or control transects to evenly distribute the number of nests between the control and treatment groups. In the fall of 2018 before ice-on, 17 treatment transects were cleaned with a pressure washer. The following spring (2019) 17 treatment transects and their paired control transects were surveyed again.

\subsection{Smallmouth Bass Nest Monitoring}

Snorkelers began at a set location and swam along shore looking for smallmouth bass nests (Fig. 1). The snorkeler moved in and out from shore as they moved along, covering the littoral zone from 0-3 $\mathrm{m}$ depth to standardize the habitat observed and because nests rarely are observed deeper than $3 \mathrm{~m}$ due to greater accumulation of organic debris, macrophyte growth, and deposited fine sediment. Once located, the snorkeler confirmed the presence of eggs or fry in the nest and that it was guarded by a male smallmouth bass and recorded the depth of the nest from the water's surface to the nearest 0.5 $\mathrm{m}$, the dominant substrate (silt/clay, sand, gravel, cobble, or bedrock) in the area and inside the nest, a categorical score for egg number used by Philipp et al. (1997) ( 1 = lowest, 5 = highest), and the estimated size of the male to the nearest $5 \mathrm{~cm}$. DMG was present for all survey dates and performed a consistency check on at least 5 nests with each swimmer before they began. Before moving on, the location of the nest was marked on a map drawn on a dive slate with a unique ID corresponding to a nest tag made of white PVC pipe left behind to avoid recounting the same nest (Fig. 2). 


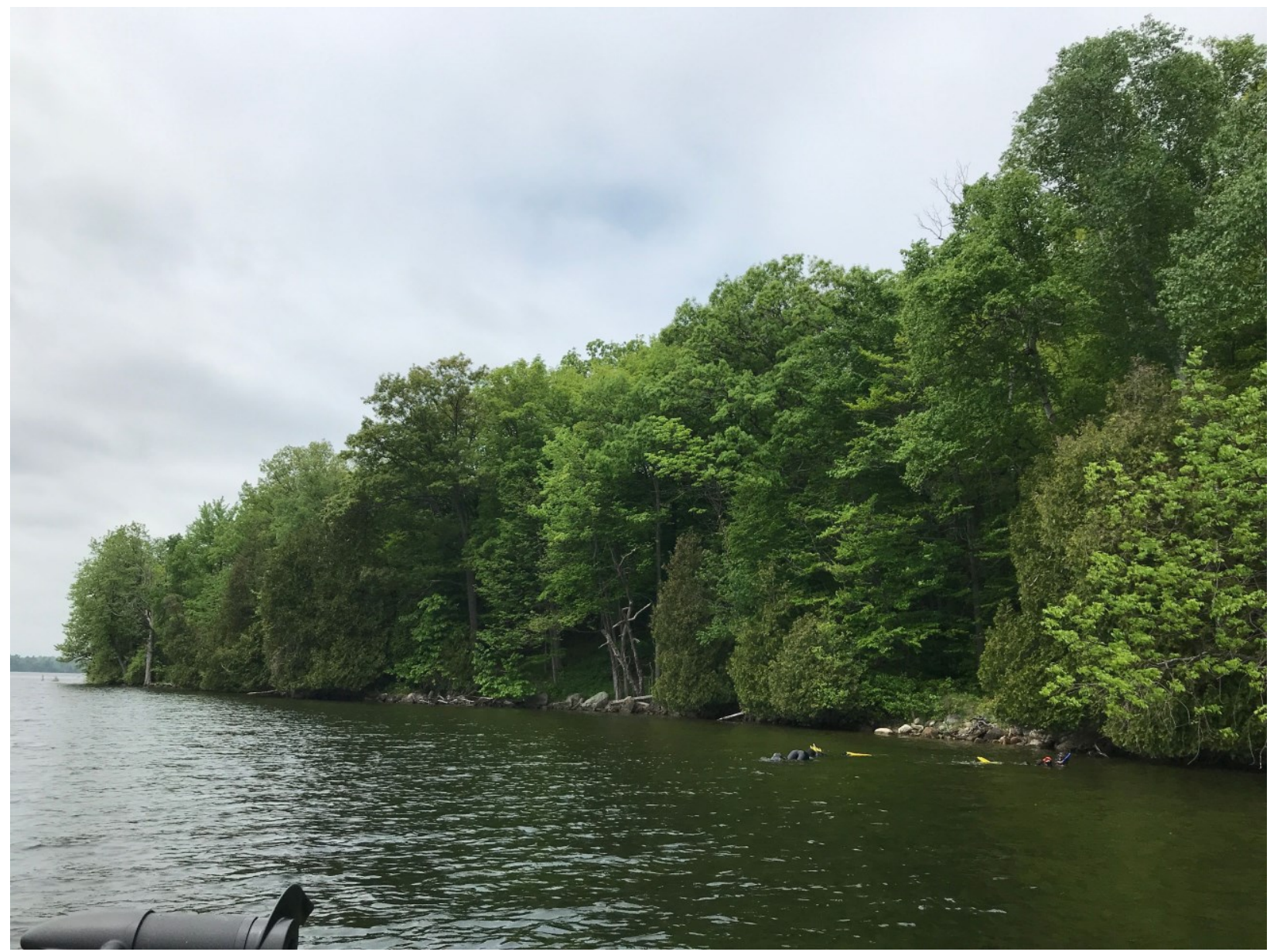

Figure 1: Example of shoreline included in the study from Big Island on Big Rideau Lake, with snorkelers surveying for nests. Taken on May 29, 2018 during baseline nest monitoring. 


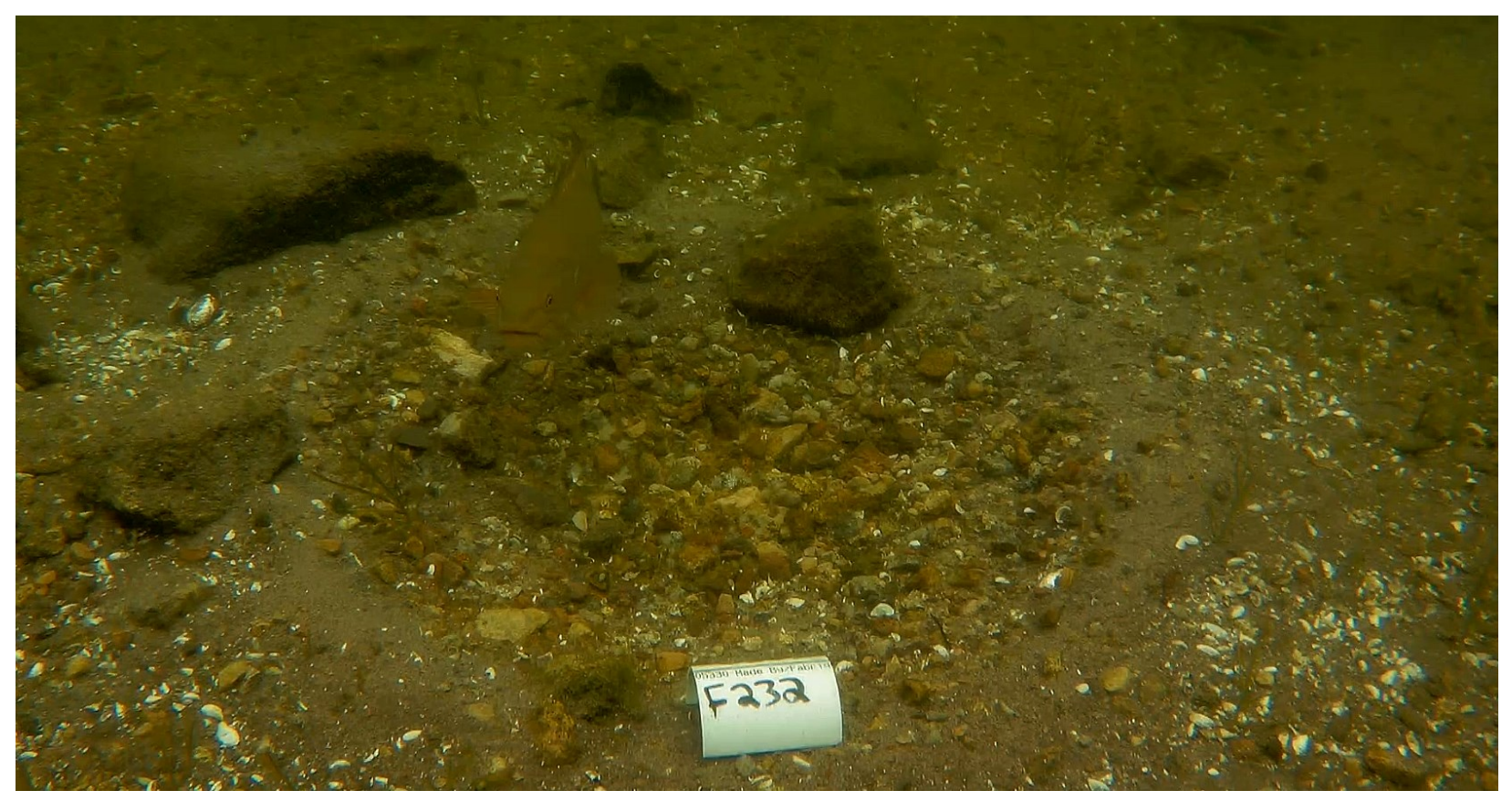

Figure 2: Photo of a smallmouth bass nest with a male guarding and a white PVC nest tag used to avoid double counting nests. The larger gravel and cobble substrate in the nest can be clearly distinguished from the surrounding fine substrate. 


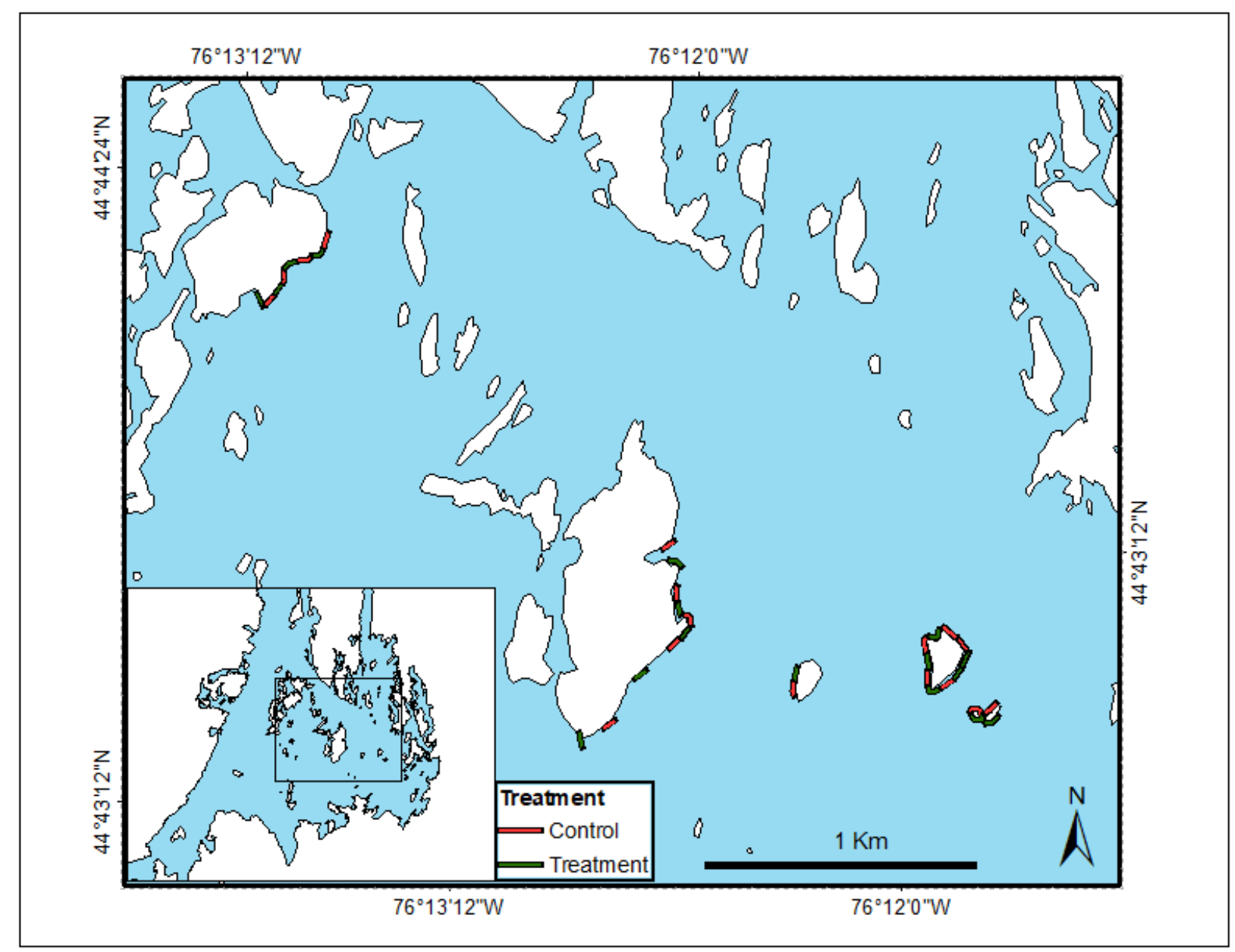

Figure 3: Map showing the locations of treatment (green) and control (red) transects on Big Rideau Lake, Ontario. 


\subsection{Treatment}

In October 2018, 17 treatment transects were cleaned with a power washer from a boat (Fig. 3). A weighted line was used to mark the $50 \mathrm{~m}$ transect roughly following the $1 \mathrm{~m}$ depth contour. Because the water level in Big Rideau Lake is regulated and drawn down in the fall to prepare for spring flooding, this corresponds roughly to the $1.5 \mathrm{~m}$ depth contour in the spring, which is the middle of the area surveyed, and the depth with the greatest number of nests. A 21 MPa gas-powered power washer was run on the deck of the boat with a $15 \mathrm{~m}$ hose connected to the spray wand with a $15^{\circ}$ nozzle, which was operated by a snorkeler (Fig. 4). The snorkeler sprayed the nozzle at an angle of roughly $30^{\circ}$ below horizontal from about $30 \mathrm{~cm}$ away pointing towards shore to remove fine sediment from a strip $1 \mathrm{~m}$ wide, while travelling along the transect (Fig. 5). The effectiveness of the substrate washing was impaired in some areas due to residual macrophyte growth from the summer however improvement in substrate quality was observed. The boat remained anchored or idling nearby and moved with the snorkeler. To ensure the cleaning did not negatively impact aquatic organisms in the area, the turbidity of the water was measured by collecting water before, and immediately after the cleaning and analyzing the sample in a Lamotte 2020e turbidity meter. 


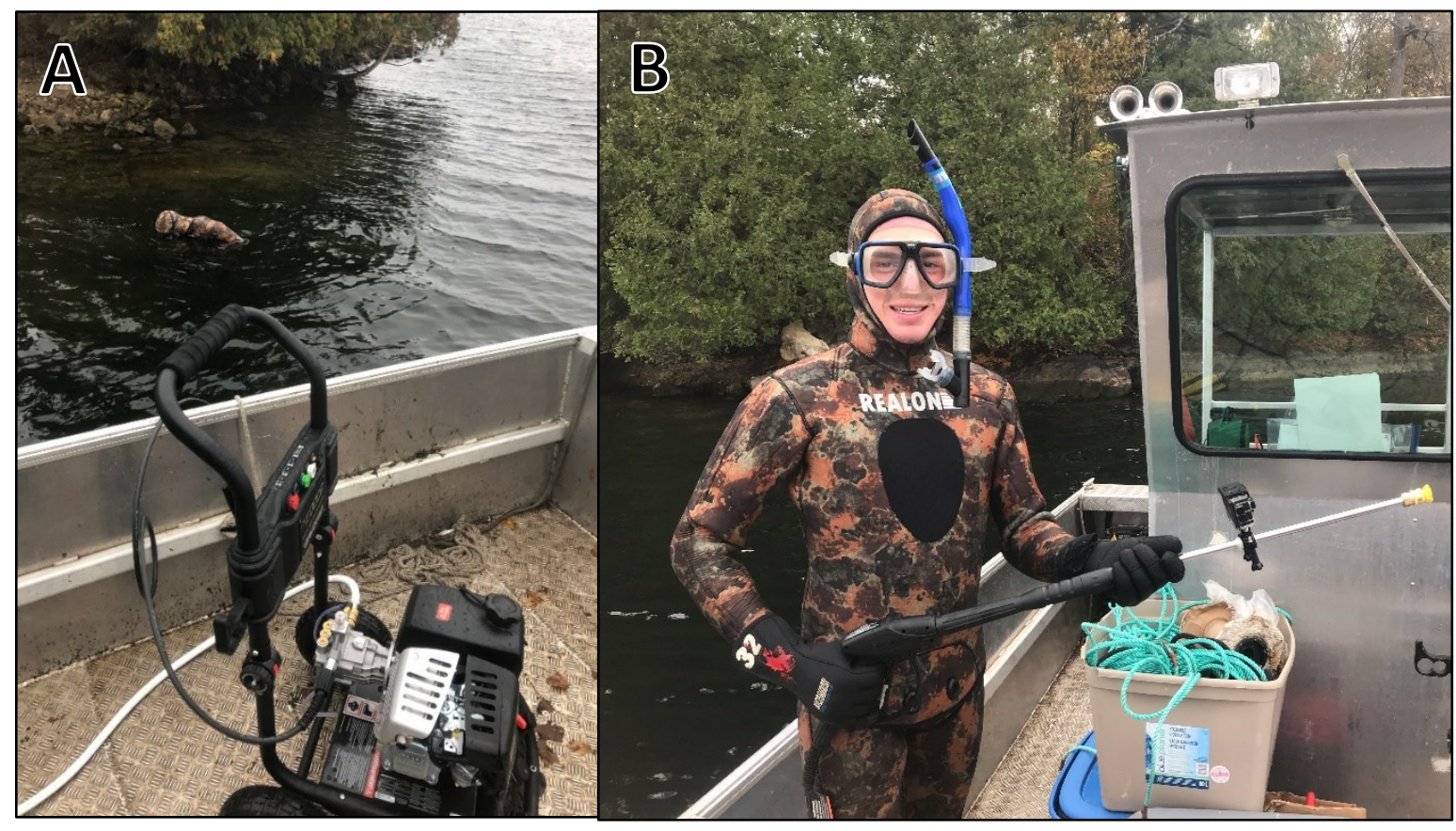

Figure 4: Picture of the gas-powered pressure washer with operator in the water $(A)$ and operator holding the spraying wand (B). The black attachment above the operator's left hand is an action camera used to record video of the restoration process. 


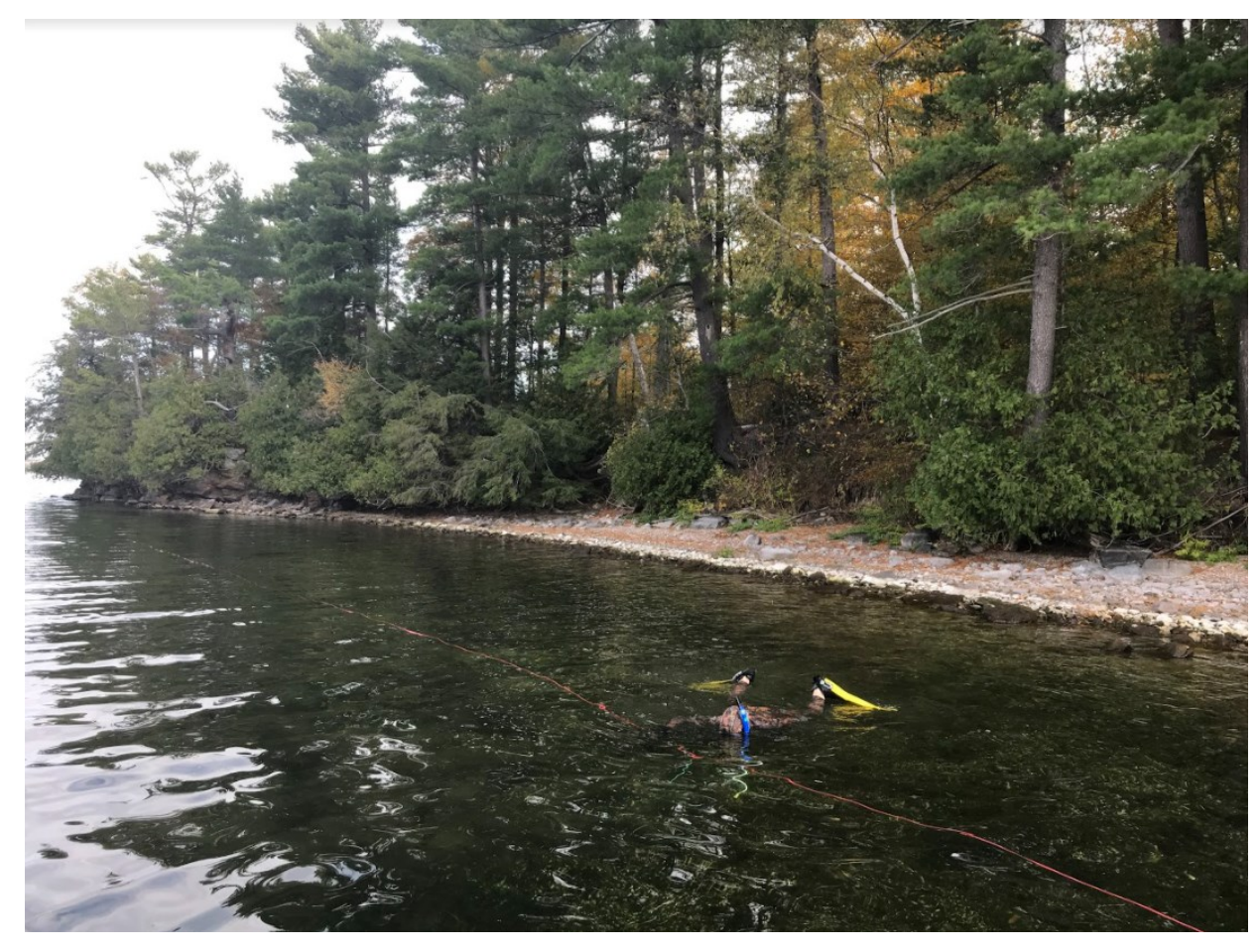

Figure 5: A red rope was used to mark the transect and the diver worked along the rope facing away from shore so the sediment plume would travel away from the spawning habitat into deeper water. Figure 2A reproduced from Baetz et al. (2020) Review of Methods to Repair and Maintain Lithophilic Fish Spawning Habitat. Water 12:1-37. 


\subsection{Data Analysis}

All statistical analyses were performed, and all figures were created in R v4.0.3 (R Core Development Team 2020). For a single before and after sampling period with multiple replicate sites, comparing the means of the change in nest abundance of the control and treatment groups with a t-test can be done instead of a two-way ANOVA test for interaction, as it provides the same result. The change in nest abundance on each transect was calculated by subtracting the 2018 abundance from the 2019 abundance. The groups passed Levene's test for equality of variance and a Shapiro-Wilk test for normal distribution, so I tested for a difference in means using an equal-variance two-tailed t-test. To test the change in average fish length, the more common two-way ANOVA test for interaction was used to compare the lengths of nesting smallmouth bass before and after restoration in the control and treatment transects.

\section{Results:}

In 2018 the locations of 92 smallmouth bass nests were mapped across 34 transects, with the first baseline survey occurring on May 28 and the last on June 4. The mean ( \pm standard error) baseline number of nests per transect was $2.53( \pm 0.50)$ in the control $(n=17)$, and $2.88( \pm 0.54)$ in the treatment groups ( $n=17)$. In 2019 the weather was colder, so the first follow-up survey took place on June 4 and the final survey occurred on June 13. The total number of nests found in 2019 was 111 , with an increase in total number of nests in both the control and treatment transects. The mean ( \pm standard error) number of nests per transect in 2019 was $2.83( \pm 0.70)$ in the control, and $3.71( \pm 1.02)$ in the treatment groups. The mean ( \pm standard error) change in nest abundance from $2018-2019$ was $0.29( \pm 0.62)$ in the control, and $0.82( \pm 1.03)$ in the treatment group. The result of the T-test found the difference of the mean change in the control and treatment groups was not statistically significant $(t=-0.440, d f=32, p=$ 0.663; Fig. 6). The mean ( \pm standard error) length of fish was similar in the control and treatment transects in 2018 at $338( \pm 4.80) \mathrm{mm}$ and $335( \pm 5.48) \mathrm{mm}$, respectively. There was a significant increase 
in average size from 2018 to 2019 overall (Two-way ANOVA, $F_{1,266}=47.51, P<0.001$ ), however the change was similar between the control and treatment groups, so the interaction of treatment and year was not significant (Two-way ANOVA, $F_{1,266}=0.09, P=0.76$ ). The mean ( \pm standard error) bass length in 2019 in the control transects was $378( \pm 5) \mathrm{mm}$, and $371( \pm 5)$ in the treatment transects (Fig. 7). While monitoring the turbidity of the water in the work area, background turbidity ranged from 0.00-3.31 NTU. Samples taken after cleaning had finished showed only a small increase ranging from 0.05-1.41 NTU, with absolute values ranging from 0.17-4.72 NTU within minutes of finishing cleaning. Although there are no federal or provincial guidelines on turbidity levels to protect aquatic life in Ontario, these values were well within the British Columbia Environmental Management Act's limit of an 8 NTU increase above baseline levels for $<24$ hours (Singleton, 2001). 


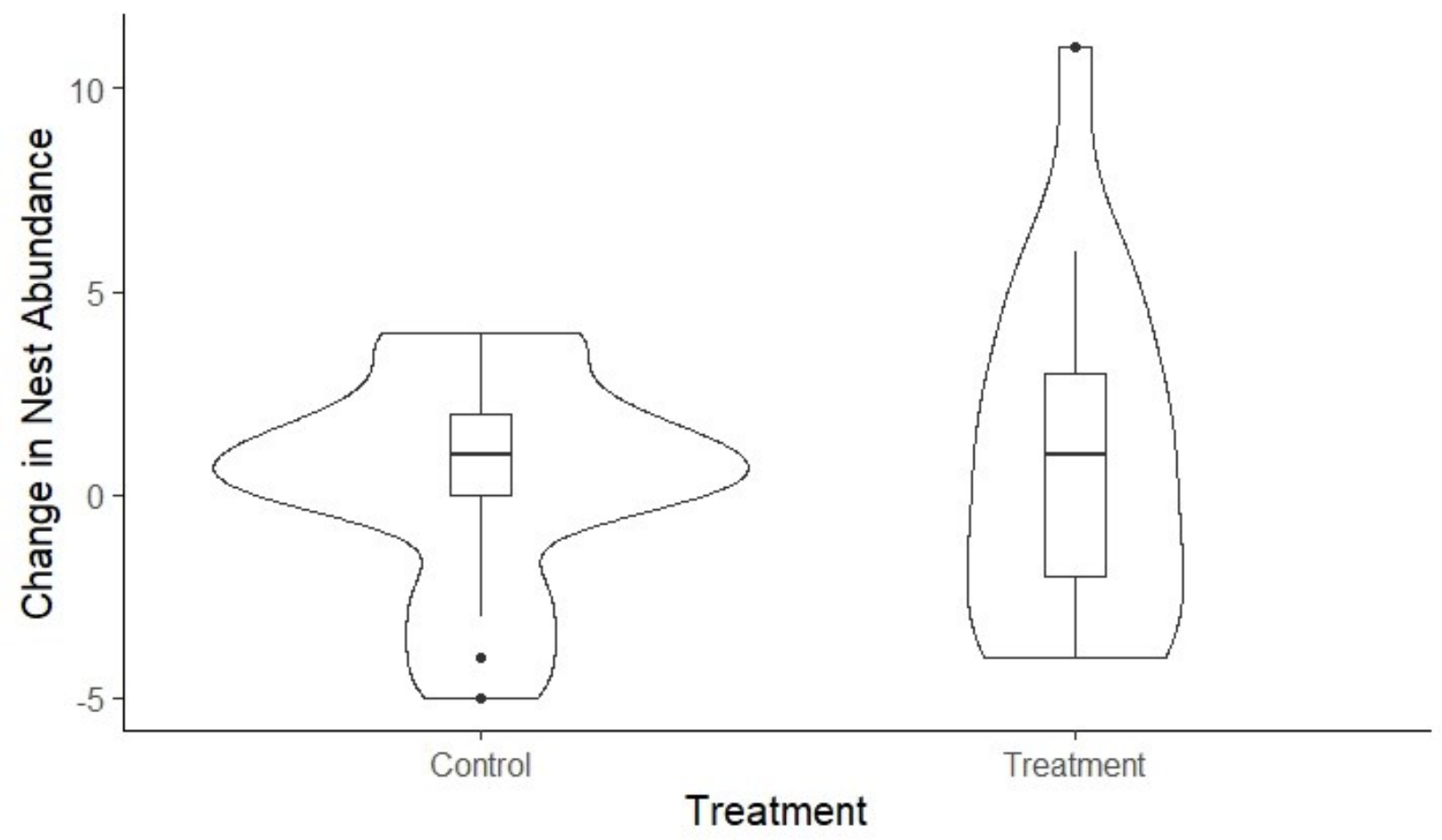

Figure 6: Boxplot of the change in nest abundance in control and cleaned spawning habitat transects. The bold horizontal line shows the median change, the upper and lower box hinges show the $75^{\text {th }}$ and $25^{\text {th }}$ percentile, and the whiskers show 1.5 times the interquartile range. Points beyond 1.5 times the interquartile range are shown with black dots. 


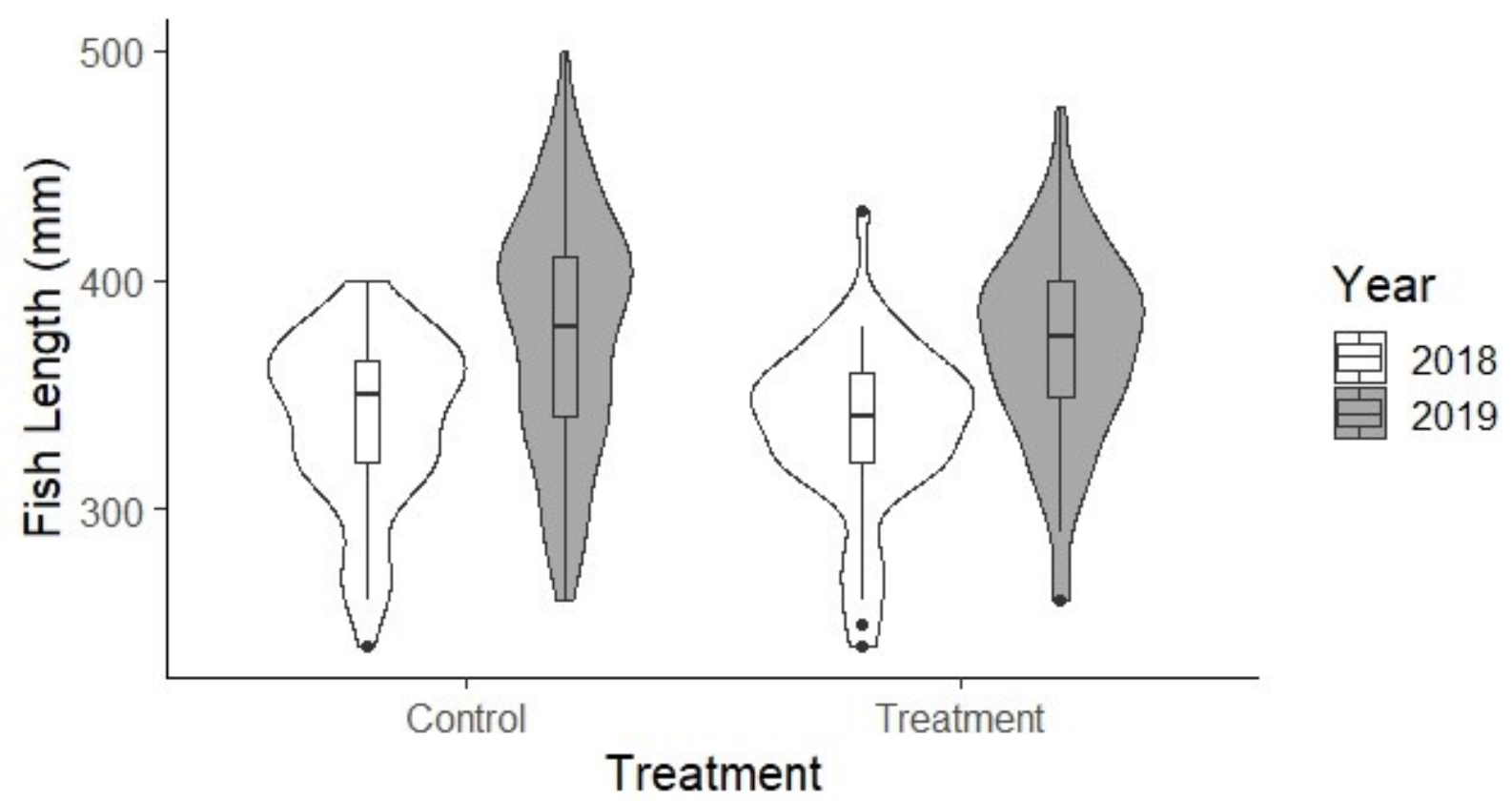

Figure 7: Violin plot showing distribution of nesting smallmouth bass lengths in control and treatment transects before (white) and after (grey) restoration. The bold horizontal line shows the median fish length, the upper and lower box hinges show the $75^{\text {th }}$ and $25^{\text {th }}$ percentile, and the whiskers show the range of values within 1.5 times the interquartile range. Points beyond 1.5 times the interquartile range are shown with black dots. 


\section{Discussion:}

Restoration is an exceedingly common activity yet rarely is it done in a coordinated manner with systematic monitoring to determine what works and what does not work (Wortley et al., 2013). This has been a particular problem for the restoration of spawning habitat for fish, where many studies suffer from low levels of replication and lacked a proper $\mathrm{BACl}$ design, rather opting for before-after or controlimpact only (Rytwinski et al., 2019). BACl design is considered the gold standard for measuring effects in environmental monitoring because when properly applied, it reduces the confounding effect of nontreatment before-after variability, or control-impact site dissimilarity on the results (Smokorowski \& Randall, 2017). Low replication in BACl studies is an issue because it reduces the generality of the results. Often in an attempt to increase sample size researchers perform pseudoreplication rather than true replication, in the form of measuring the response at multiple times or locations within a single unit (Johnson, 2002).

I performed a high level of replication for a study in this field by performing the treatment in many discrete patches and measuring the change in abundance at each to find the average effect of the treatment across multiple units, rather than the average change within a larger site. By performing true replication I also made these results robust against chance variation in the control and impact sites, which can significantly confound the results at low sample sizes and is identified as a fatal flaw in $\mathrm{BACl}$ studies with limited replication (Underwood, 1992; Conquest, 2000). I also had the benefit of being able to randomly assign control and impact sites, which were selected with consideration for physical proximity and similarity regarding habitat quality and number of nests in the before period (Smith, 2014). Ideally, a BACl experiment uses multiple years of before and after monitoring to get a better understanding of interannual variability and observe if the effect of intervention is delayed or shortlived (Smokorowski \& Randall, 2017). Due to the time constraints of this study, only one year of before data could be collected. The effect of the treatment was expected to be immediate due to selection of 
superior nesting habitat by bass, and short-lived due to continued sedimentation of the site. A sudden and short-lived effect can be viewed as a "pulse," in which case testing only the sampling period immediately after the impact to the before period is preferable to avoid diluting the effect by including time after the effect has passed (Underwood, 1992). Therefore, I decided on one year of follow-up monitoring, with the possibility of subsequent monitoring to determine the longevity of the benefit if there was a measured effect in the first year. It is possible that a longer period between treatment and response could occur due to increased egg survival in the restored habitat leading to larger year classes, but as the objective was to examine nest selection, monitoring for long-term effects was beyond the scope of this study.

Pressure washing of smallmouth spawning substrate did not increase the abundance of nests the following year relative to the control. Although the cleaning appeared to reduce the amount of fine sediment and degree of embeddedness in the areas treated immediately after (Fig. 8), the cleaned areas were indistinguishable from their immediate surroundings during follow-up monitoring seven months later (pers. observation). Other studies have found that substrate cleaning with pressurized water led to short-lived improvements in sediment size composition and substrate permeability (Sepulveda et al., 2015; Bašić et al., 2017). Between the time the cleaning treatment was applied and the next spawning period, three periods of disturbance occurred which could cause resettlement of sediment in the cleaned area and reduce the impact of the treatment: fall turnover, ice breakup, and spring turnover. During fall and spring turnover, sediment is resuspended and evenly dispersed throughout the lake, and during ice breakup ice sheets can be moved by wind or currents to disturb littoral sediment or be thrust against shorelines and erode sediment into the lake. I chose shoreline habitat on mid-lake islands to test this method because the limited catchment area relative to the habitat area would minimize terrestrial sediment inputs. Shortening the interval between cleaning and spawning could result in a stronger treatment effect. However, due to winter ice cover, frigid spring temperatures, and the use of the same 


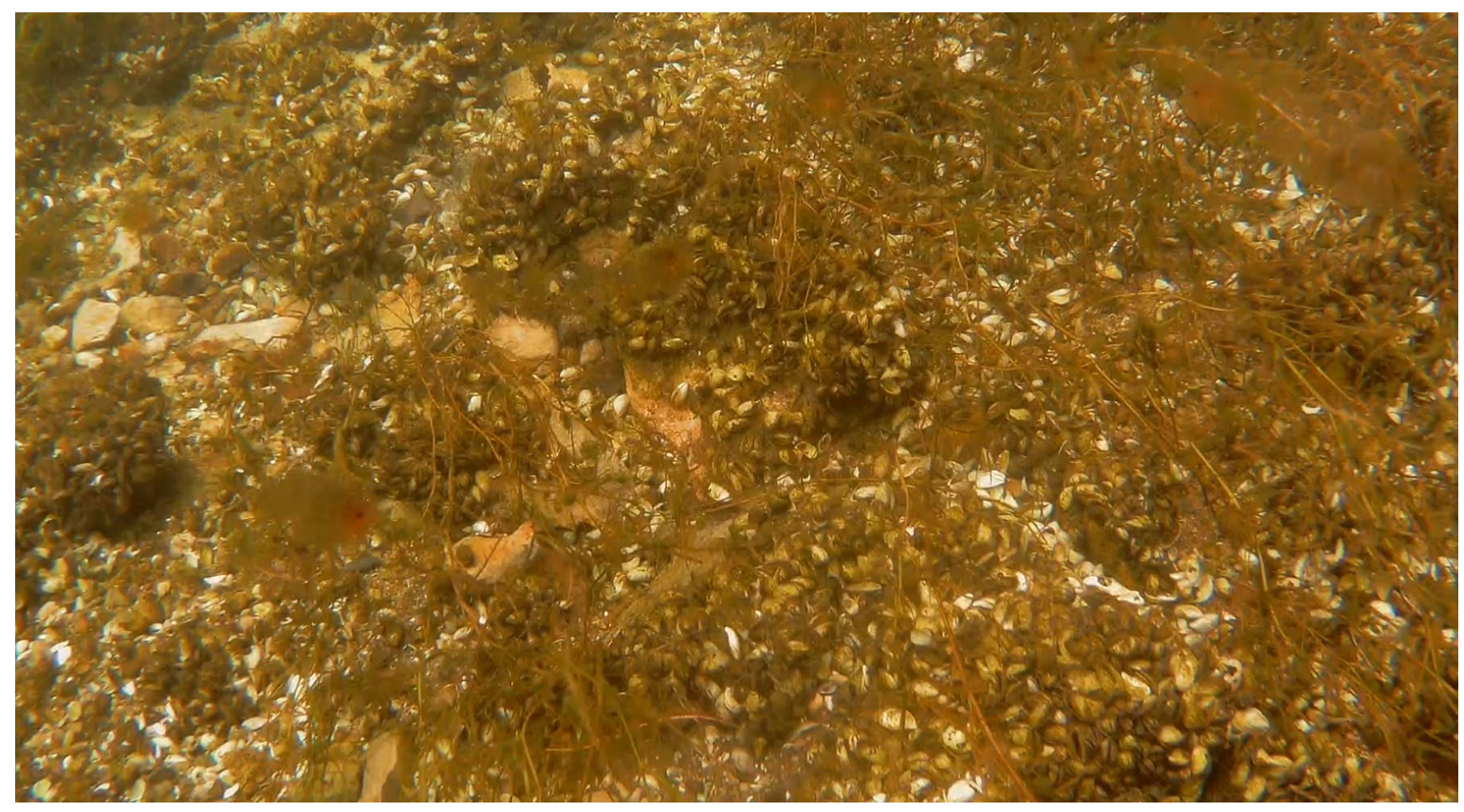

Figure 8: Picture taken following substrate cleaning. The left side of the image is the treated area, and the right is untreated. Improvement in substrate quality can be seen through the reduction in biofilm, vegetation and organic sediment which make the untreated side darker, and increased visibility of larger substrates in the treated section. 
habitat by other spawning species in the spring, it was not possible to perform the cleaning closer to the smallmouth spawning period.

There is a strong bias in published studies of spawning habitat restoration, and in particular gravel and cobble washing, towards species of the salmonid family (Taylor et al., 2019), so the most relevant comparison studies are on salmon and trout. Observational studies have established a correlation between spawning habitat variables such as substrate size, hydraulic conductivity, or porewater dissolved oxygen and egg survival (Lapointe et al., 2004), so many studies measure these variables as an indicator for increased reproductive potential of a site. Several studies have shown that gravel washing with specialized tools as well as basic pumps and power washers can improve the conditions of spawning gravel in terms of sediment composition, hydraulic conductivity, and dissolved oxygen. Fewer studies have measured whether these improvements have been accompanied by improvements in biological variables. A study in Idaho of a gravel washing tool found significant reduction of fine sediment in the surface and subsurface of the spawning site but failed to find any change in cutthroat trout biomass (Sepulveda et al., 2015). Pulg et al. (2014) found that gravel cleaning with the more invasive method of substrate excavation and redeposition led to reduced fine sediment, increased survival of eggs, and increased young of the year brown trout for 2 years post-restoration until the substrate became clogged again.

Although there has been evidence of increased reproductive success from gravel washing, as measured by egg survival rates or young of the year abundance, there is little information about whether gravel washing affects spawning habitat selection in fish. Salmonids have strong fidelity to their natal stream when selecting spawning habitat, and since many salmonids semelparous and spend their non-reproductive life stages in a different habitat than their spawning habitat, it is hard to know if they would find and use improved habitat over degraded habitat. Pulg et al. (2014) found that after cleaning gravel, the number of trout and grayling spawning in a degraded chalk stream increased, however it is 
important to note that the area of suitable habitat increased substantially, from $1.5-14 \%$ of the river area. Salmonids are generally less tolerant of low dissolved oxygen than smallmouth bass, and their eggs are particularly susceptible to issues caused by fine sediment accumulation in their spawning habitat (Tang et al., 2020), so their spawning habitat requirements are more specific and they may not attempt to spawn without high-quality habitat.

Smallmouth are considered neither tolerant nor intolerant of low dissolved oxygen (Tang et al., 2020), so they have wider habitat requirements and are more likely to be able to spawn in lower quality habitat. Since smallmouth are more tolerant of marginal spawning habitat conditions, this restoration may have improved the quality of the habitat but not have increased the amount of suitable habitat. My method of monitoring which enumerated all smallmouth nests in the littoral zone of each transect, rather than just the area treated, was used to see if there was an overall increase in smallmouth nests in the area, not just a redistribution of nests into the treated area. If the entire area that was cleaned had been suitable habitat already, there would not be an increase in habitat area and nest distribution may have changed without affecting abundance. To better understand if this treatment affected nest site selection and abundance, designating the treatment plot with permanent markers, and counting the number of nests within the plot and the overall area in the before and after monitoring would give better insight to whether there was redistribution within the transect to the treatment plot in addition to whether the treatment affects the overall local abundance.

During the period before spawning occurred, I noticed smallmouth nests from previous years were still visible as bowl-shaped depressions with larger substrate covered in a thin layer of fine sediment buildup and periphyton or biofilm accumulation since they had been used. Smallmouth bass often show nest site fidelity, nesting in the same area in successive years (Ridgway et al., 1991a; Barthel et al., 2008). I observed many of these existing depressions from previous years were reused by smallmouth, which would reduce the energy required to prepare the nest. It is possible that the way I 
applied the cleaning treatment, which was to clean a $50 \mathrm{~m} \times 1 \mathrm{~m}$ strip of substrate failed to attract bass because it did not resemble the natural cues they use to select potential sites. Additionally, because of the amount of area that was targeted, the treatment was somewhat superficial and only affected the top layer of substrate. Cleaning out an existing depression would save more energy for a nesting bass to devote towards parental care than having to excavate a depression in a large area of slightly cleaner substrate, so maybe the restoration treatment should be more focused and applied in patches. If the treatment attempted to recreate the form of previous nests by focussing the effort on several spots along the transect and excavating a bowl-shaped depression $0.5 \mathrm{~m}$ in diameter and $5 \mathrm{~cm}$ deep, this could be more attractive to a male bass looking for a spawning site than a large area of superficial cleaning. Male smallmouth bass show some territoriality towards male conspecifics when nesting, so nests are usually spaced out. Using a patch approach would be more efficient therefore by leaving space between potential nest sites. Another advantage of a patch approach would be that if successful, how variables such as proximity to structure, spacing, and water depth impact the probability of selection by bass could be easily measured, leading to improvement in the method.

There was a noticeable transition from cleaner, less embedded substrate to more embedded substrate with more zebra mussels above the depth that the cleaning took place, which I had not noticed when performing the baseline survey. This is the resuspension depth, above which wave action prevents small sediment from settling. The depth this occurs at is dependent on the amount of wave energy experienced in the area, which for mid-lake islands in a lake with a large fetch can be significant. Based on my observations, the resuspension depth in the areas observed was about $1 \mathrm{~m}$, which corresponded to the depth that most smallmouth nests were found at or above. Provided water levels remain at a depth that includes suitable substrates within the resuspension depth, this process should naturally maintain an abundance of spawning habitat free from sedimentation. A study of several guilds of fish in the Bay of Quinte, Lake Ontario, showed that water levels have a significant impact on the 
availability of habitat for shallow-spawning substrate-dependent fish including smallmouth bass (Gertzen et al., 2012) and studies in other systems on species with similar needs agree (Rowe et al., 2002; Hardie \& Chilcott, 2017).

\section{Future Research Directions:}

Further research on spawning substrate cleaning is needed to determine if it can be used as an effective habitat restoration tool. This study found it to be ineffective at increasing the number of nesting bass in an area, however, other indicators of reproductive success could tell a different story. Although many males may reach the stage of making a nest and courting a female to deposit eggs, which was our measure of success, a large-scale 20-year study of smallmouth reproduction found on average around half of males end up abandoning their brood before they reach independence (Suski \& Ridgway, 2007). Nest abandonment is believed to be a cost-benefit analysis by male bass, with increasing likelihood as the viability of the brood decreases through mortality due to factors including nest predation, storms, climate, pathogens, or hypoxia (Lukas \& Orth, 1995; Dauwalter \& Fisher, 2007; Suski \& Ridgway, 2007; Kaemingk et al., 2011). If substrate cleaning leads to increased nest success and increased survival in nests, then the restoration can be considered successful, similar to how some salmonid habitat restoration studies measure egg development success (Shackle et al., 1999; Pulg et al., 2014). Studying whether habitat restoration affects brood mortality, and the probability of nest abandonment could provide a more sensitive indicator the effectiveness of substrate cleaning, and further test our understanding of the factors which lead to nest abandonment. There is also opportunity to assess differences in oxygen levels within nests to determine if there are any benefits to developing offspring. Smallmouth bass egg and larvae survival is reduced in water with dissolved oxygen below 5 $\mathrm{mg} / \mathrm{L}$, giving a good threshold target for measurements of dissolved oxygen in nests (Siefert et al., 1974; Spoor, 1984). Measuring how restoration affects the physiochemical conditions within nests will enable 
better understanding of the mechanisms behind the resultant effects, or lack thereof, on reproductive success in smallmouth bass, which will allow better refinement of methods intended to improve them.

In addition to testing alternative measures of restoration success, testing the gravel cleaning method in different environments could lead to different results. Smallmouth bass are a widely distributed species found in a diversity of habitats, including fluvial systems where routine scour may be a more common phenomenon. Flow modification and habitat fragmentation in rivers caused by road crossings and water resource development is a ubiquitous issue, causing a loss of natural hydrologic cycles, and sediment build-up in critical spawning habitat (Liermann et al., 2012; Maitland et al., 2016). Removal of water control structures and road crossings to return natural flow regimes has gained popularity as a river restoration method, however it can lead to short-term increases in sediment delivered to downstream habitats (Bednarek, 2001). As substrate cleaning has been shown to work in rivers to improve salmonid spawning success, testing the effectiveness at improving smallmouth bass reproduction in a more similar environment may be good intermediate step between the current study and the previous studies. Substrate cleaning could be a useful tool for maintaining smallmouth bass spawning habitat quality in rivers which have lost their natural hydrologic cycle, or as a follow-up treatment to reduce the impact of dam removal. Furthermore, land cover conversion for agricultural use and urban development increase inputs of sediment and negatively impact water quality in streams (Maitland et al., 2016). In a variety of situations in degraded streams and rivers, artificial cleaning of substrate may prove beneficial for smallmouth bass spawning habitat and deserves further study.

\section{Conclusion:}

I found that substrate cleaning with pressurized water did not increase the abundance of smallmouth bass nests in sedimented spawning habitat. Because of the quality of the experimental design, I believe these results are credible and provide strong evidence that pressure washing as I 
applied it is not an effective habitat enhancement method in a lacustrine environment. It is possible that natural disturbance between the time of cleaning and use of the site neutralized the effect of the cleaning. Additionally, I note that water levels that maintain suitable substrate within the resuspension zone of the lake may provide sufficient high-quality smallmouth bass nesting habitat in Big Rideau Lake so that it is not a limiting factor for the population. Although the design of this study does not enable testing of these hypotheses, the observations made provide possible avenues for future studies and improvements of the method. Perhaps in an area with more severely impacted spawning habitat there would be a more pronounced change, leading to greater benefit. So, even though the restoration was unsuccessful, the monitoring program may be considered a success, as it provided strong evidence that further efforts with the same method would not be a good use of resources and helped determine new avenues of inquiry that may lead to better smallmouth bass nesting habitat restoration in the future.

To live up to the ambitions of the UN Decade on Ecosystem Restoration we need to drastically improve our understanding of ecosystem restoration (Cooke et al., 2019). This will require strong monitoring of restoration effects to improve our methods, provide evidence of value for effort, and guide evidence-based environmental management. Monitoring of aquatic habitat restoration particularly requires improvement because of the current lack of strong evidence for efficacy, and because the effects are often out of sight. Without measuring progress in a scientifically robust fashion, we cannot know when our efforts are being wasted or even we have achieved our goals (Mahlum et al., 2018). Despite the immense socio-economic value of freshwater fisheries spanning the recreational, commercial, and Indigenous sectors, they are often underappreciated (Cooke et al. 2016). Improving the monitoring of habitat restoration projects and using statistical methods which produce easily interpreted results, such as Bayesian inference, will further improve the value of the knowledge generated by making it accessible to stakeholders and more effectively applied in decision-making (Conner et al., 2016). By using stakeholder values to guide restoration target selection and measuring 
and communicating results in ways which are understandable to stakeholders, we can use the opportunity of the UN Decade on Ecosystem Restoration to drive greater engagement and support for habitat restoration in this decade and beyond. 


\section{References:}

Baetz, A., T. R. Tucker, R. L. Debruyne, A. Gatch, T. Höök, J. L. Fischer, \& E. F. Roseman, 2020. Review of Methods to Repair and Maintain Lithophilic Fish Spawning Habitat. Water 12: 1-37.

Barthel, B. L., S. J. Cooke, J. H. Svec, C. D. Suski, C. M. Bunt, F. J. S. Phelan, \& D. P. Philipp, 2008.

Divergent life histories among smallmouth bass Micropterus dolomieu inhabiting a connected river-lake system. Journal of Fish Biology 73: 829-852, http://doi.wiley.com/10.1111/j.1095-8649.2008.01972.x.

Bašić, T., J. R. Britton, S. P. Rice, \& A. G. Pledger, 2017. Impacts of gravel jetting on the composition of fish spawning substrates: Implications for river restoration and fisheries management. Ecological Engineering 107: 71-81.

Bednarek, A. T., 2001. Undamming rivers: A review of the ecological impacts of dam removal. Environmental Management 27: 803-814.

Bozek, M. A., P. H. Short, C. J. Edwards, M. J. Jennings, \& S. P. Newman, 2002. Habitat selection of nesting smallmouth bass Micropterus dolomieu in two north temperate lakes. American Fisheries Society Symposium 2002: 135-148.

Carpenter, S. R., E. H. Stanley, \& M. J. Vander Zanden, 2011. State of the world's freshwater ecosystems: Physical, chemical, and biological changes. Annual Review of Environment and Resources 36: 75-99.

Conner, M. M., W. C. Saunders, N. Bouwes, \& C. Jordan, 2016. Evaluating impacts using a BACI design, ratios, and a Bayesian approach with a focus on restoration. Environmental Monitoring and Assessment Environmental Monitoring and Assessment 188:, http://dx.doi.org/10.1007/s10661-016-5526-6.

Conquest, L. L., 2000. Analysis and Interpretation of Ecological Field Data Using BACI Designs : Discussion. Journal of Agricultural , Biological , and Environmental Statistics 5: 293-296.

Cooke, S. J., J. R. Bennett, \& H. P. Jones, 2019. We have a long way to go if we want to realize the 
promise of the "Decade on Ecosystem Restoration." Conservation Science and Practice 1: 1-5.

Cooke, S. J., \& G. R. Wilde, 2007. The Fate of Fish Released by Recreational Anglers. 181-234.

Dauwalter, D. C., \& W. L. Fisher, 2007. Spawning chronology, nest site selection and nest success of smallmouth bass during benign streamflow conditions. American Midland Naturalist 158: 60-78.

DeAngelis, D. L., L. Godbout, \& B. J. Shuter, 1991. An individual-based approach to predicting densitydependent dynamics in smallmouth bass populations. Ecological Modelling 57: 91-115.

Gertzen, E. L., S. E. Doka, C. K. Minns, J. E. Moore, \& C. Bakelaar, 2012. Effects of water levels and water level regulation on the supply of suitable spawning habitat for eight fish guilds in the Bay of Quinte, Lake Ontario. Aquatic Ecosystem Health and Management 15: 397-409.

Gingerich, A. J., \& C. D. Suski, 2011. The role of progeny quality and male size in the nesting success of smallmouth bass: integrating field and laboratory studies. Aquatic Ecology Springer Netherlands 45: 505-515, http://link.springer.com/10.1007/s10452-011-9371-y.

Gravel, M. A., P. Couture, \& S. J. Cooke, 2010. Comparative energetics and physiology of parental care in smallmouth bass Micropterus dolomieu across a latitudinal gradient. Journal of Fish Biology 76: 280300.

Hardie, S. A., \& M. A. Chilcott, 2017. Water levels in a highland lake control the quantity and quality of spawning habitat for a littoral-spawning galaxiid fish. Aquatic Conservation: Marine and Freshwater Ecosystems 27: 24-38.

Harrison, I., R. Abell, W. Darwall, M. L. Thieme, D. Thickner, \& I. Timboe, 2018. The freshwater biodiversity crisis. Science 362: 1369.

Hinch, S. G., \& N. C. Collins, 1991. Importance of diurnal and nocturnal nest defense in the energy 
budget of male smallmouth bass: Insights from direct video observations. Transactions of the American Fisheries Society 120: 657-663.

Hoekstra, J. M., T. M. Boucher, T. H. Ricketts, \& C. Roberts, 2005. Confronting a biome crisis: Global disparities of habitat loss and protection. Ecology Letters 8: 23-29.

Hughes, K., 2021. The World's Forgotten Fishes. GLand, Switzerland.

Jennions, M. D., \& A. P. Møller, 2002. Publication bias in ecology and evolution: An empirical assessment using the "trim and fill" method. Biological Reviews of the Cambridge Philosophical Society 77: 211-222.

Johnson, D. H., 2002. The Importance of Replication in Wildlife Research. .

Kaemingk, M. A., A. Clem, \& T. L. Galarowicz, 2011. The influence of habitat and environment on smallmouth bass (Micropterus dolomieu) nest sites and nest success in northern Lake Michigan. Journal of Great Lakes Research 37: 380-385.

Kaufmann, P. R., D. V. Peck, S. G. Paulsen, C. W. Seeliger, R. M. Hughes, T. R. Whittier, \& N. C. Kamman, 2014. Lakeshore and littoral physical habitat structure in a national lakes assessment. Lake and Reservoir Management 30: 192-215.

Lapointe, M. F., N. E. Bergeron, F. Bérubé, M. A. Pouliot, \& P. Johnston, 2004. Interactive effects of substrate sand and silt contents, redd-scale hydraulic gradients, and interstitial velocities on egg-toemergence survival of Atlantic salmon (Salmo salar). Canadian Journal of Fisheries and Aquatic Sciences 61: 2271-2277.

Lawson, Z. J., J. W. Gaeta, S. R. Carpenter, Z. J. Lawson, J. W. Gaeta, S. R. Carpenter, Z. J. Lawson, J. W. Gaeta, \& S. R. Carpenter, 2011. Coarse Woody Habitat, Lakeshore Residential Development , and Largemouth Bass Nesting Behavior. 5947:. 
Liermann, C. R., C. Nilsson, J. Robertson, \& R. Y. Ng, 2012. Implications of Dam Obstruction for Global Freshwater Fish Diversity. BioScience 62: 539-548, https://academic.oup.com/bioscience/articlelookup/doi/10.1525/bio.2012.62.6.5.

Lukas, J. A., \& D. J. Orth, 1995. Factors Affecting Nesting Success of Smallmouth Bass in a Regulated Virginia Stream. Transactions of the American Fisheries Society 124: 726-735.

Lynch, A. J., S. J. Cooke, A. M. Deines, S. D. Bower, D. B. Bunnell, I. G. Cowx, V. M. Nguyen, J. Nohner, K. Phouthavong, B. Riley, M. W. Rogers, W. W. Taylor, W. Woelmer, S. J. Youn, \& T. D. Beard, 2016. The social, economic, and environmental importance of inland fish and fisheries. Environmental Reviews 24: $115-121$.

Mackereth, R. W., D. L. G. Noakes, \& M. S. Ridgway, 1999. Size-Based Variation in Somatic Energy Reserves and Parental Expenditure by Male Smallmouth Bass, Micropterus dolomieu. Environmental Biology of Fishes 56: 263-275.

Mahlum, S., D. Cote, Y. F. Wiersma, C. Pennell, \& B. Adams, 2018. Does restoration work? It depends on how we measure success. Restoration Ecology 26: 952-963.

Maitland, B. M., M. Poesch, A. E. Anderson, \& S. N. Pandit, 2016. Industrial road crossings drive changes in community structure and instream habitat for freshwater fishes in the boreal forest. Freshwater Biology 61: 1-18.

MARN (Ministerio deMedio Ambiente y Recursos Naturales), 2019. UN decade of ecosystem restoration 2021-2030. .

Mih, W. C., \& G. C. Bailey, 1981. The Development of a Machine for the Restoration of Stream Gravel for Spawning and Rearing of Salmon. Fisheries 6: 16-20, http://www.tandfonline.com/doi/abs/10.1577/1548-8446-6-6. 
Miller, J. R., \& R. J. Hobbs, 2016. Habitat Restoration - Do We Know What We' re Doing? Restoration Ecology 15;3: 382-390.

Naeem, S., D. E. Bunker, A. Hector, M. Loreau, \& C. Perrings, 2009. Biodiversity, Ecosystem Functioning, and Human Wellbeing: An Ecological and Economic Perspective. Biodiversity, Ecosystem Functioning, and Human Wellbeing: An Ecological and Economic Perspective. Oxford University Press.

NatureServe, 2013. Micropterus dolomieu. The IUCN Red List of Threatened Species 2013:

e.T202564A18230216. IUCN , http://dx.doi.org/10.2305/IUCN.UK.2013-1.RLTS.T202564A18230216.en.

Philipp, D. P., C. A. Toline, M. F. Kubacki, D. B. F. Philipp, \& F. J. S. Phelan, 1997. The Impact of Catch-andRelease Angling on the Reproductive Success of Smallmouth Bass and Largemouth Bass. North American Journal of Fisheries Management 17: 557-567.

Pulg, U., B. T. Barlaup, K. Sternecker, L. Trepl, \& G. Unfer, 2014. Restoration of Spawning Habitats of Brown Trout (Salmo trutta) in a Regulated Chalk Stream. River Research and Applications 30: 132-133.

Raffetto, N. S., J. R. Baylis, \& S. L. Serns, 1990. Complete Estimates of Repreductive Success in a Closed Population of Smallmouth Bass (Micropterus Dolomieui). 71: 1523-1535.

Ridgeway, M. S., \& B. J. Shuter, 1996. Effects of Displacement on the Seasonal Movements and Home Range Characteristics of Smallmouth Bass in Lake Opeongo. North American Journal of Fisheries Management 16: 371-377.

Ridgway, M. S., J. A. MacLean, \& C. J. MacLeod, 1991a. Nest-site fidelity in a centrarchid fish, the smallmouth bass (Micropterus dolornieui). Canadian Journal of Zoology 69: 3103-3105.

Ridgway, M. S., B. J. Shuter, \& E. E. Post, 1991b. The Relative Influence of Body Size and Territorial Behaviour on Nesting Asynchrony in Male Smallmouth Bass, Micropterus dolomieui ( Pisces : Centrarchidae ). Journal of Animal Ecology 60: 665-681. 
Roni, P., T. J. Beechie, R. E. Bilby, F. E. Leonetti, M. M. Pollock, \& G. R. Pess, 2002. A Review of Stream Restoration Techniques and a Hierarchical Strategy for Prioritizing Restoration in Pacific Northwest Watersheds. North American Journal of Fisheries Management 22: 1-20.

Rowe, D. K., U. Shankar, M. James, \& B. Waugh, 2002. Use of GIS to predict effects of water level on the spawning area for smelt, Retropinna retropinna, in Lake Taupo, New Zealand. Fisheries Management and Ecology 9: 205-216.

Rytwinski, T., L. K. Elmer, J. J. Taylor, L. A. Donaldson, J. R. Bennett, K. E. Smokorowski, A. K. Winegardner, \& S. J. Cooke, 2019. How effective are spawning-habitat creation or enhancement measures for substrate-spawning fish? A synthesis. Canadian Technical Report of Fisheries and Aquatic Sciences. .

Sepulveda, A. J., M. Layhee, Z. A. Sutphin, \& J. D. Sechrist, 2015. Evaluation of a fine sediment removal tool in spring-fed and snowmelt driven streams. Ecological Restoration 33: 303-315.

Shackle, V. J., S. Hughes, \& V. T. Lewis, 1999. The influence of three methods of gravel cleaning on brown trout, Salmo trutta, egg survival. Hydrological Processes 13: 477-486.

Siefert, R. E., A. R. Carlson, \& L. J. Herman, 1974. Effects of reduced oxygen concentrations on the early life stages of mountain whitefish, smallmouth bass, and white bass. Progressive Fish-Culturist 36: 186190, https://doi.org/10.1577/1548-8659(1974)36[186:EOROCO]2.0.CO;2.

Singleton, H., 2001. Ambient water quality guidelines (criteria) for turbidity, suspended and benthic sediments: Overview report. Victoria, BC.

Smith, E. P., 2014. BACI Design. Wiley StatsRef: Statistics Reference Online 1: 141-148.

Smokorowski, K. E., \& R. G. Randall, 2017. Cautions on using the Before-After-Control-Impact design in environmental effects monitoring programs. Facets 2: 212-232. 
Spoor, W. A., 1984. Oxygen requirements of larvae of the smallmouth bass, Micropterus dolomieui Lacépède. Journal of Fish Biology 25: 587-592.

Suding, K., E. Higgs, M. Palmer, J. B. Callicott, C. B. Anderson, M. Baker, J. J. Gutrich, K. L. Hondula, M. C. LaFevor, B. M. H. Larson, A. Randall, J. B. Ruhl, \& K. Z. S. Schwartz, 2015. Committing to ecological restoration. Science 348: 638-640.

Suski, C. D., \& M. S. Ridgway, 2007. Climate and body size influence nest survival in a fish with parental care. Journal of Animal Ecology 76: 730-739.

Tang, R. W. K., S. E. Doka, E. L. Gertzen, \& L. M. Neigum, 2020. Dissolved oxygen tolerance guilds of adult and juvenile Great Lakes fish species. Canadian Manuscript Report of Fisheries and Aquatic Sciences. , http://waves-vagues.dfo-mpo.gc.ca/Library/40857463.pdf.

Tappel, P. D., \& T. C. Bjornn, 1983. A New Method of Relating Size of Spawning Gravel to Salmonid Embryo Survival. North American Journal of Fisheries Management 3: 123-135.

Taylor, J. J., T. Rytwinski, J. R. Bennett, K. E. Smokorowski, N. W. R. Lapointe, R. Janusz, K. Clarke, B. Tonn, J. C. Walsh, \& S. J. Cooke, 2019. The effectiveness of spawning habitat creation or enhancement for substrate-spawning temperate fish: A systematic review. Environmental Evidence BioMed Central 8: 1-31, https://doi.org/10.1186/s13750-019-0162-6.

Tickner, D., J. J. Opperman, R. Abell, M. Acreman, A. H. Arthington, S. E. Bunn, S. J. Cooke, J. Dalton, W. Darwall, G. Edwards, I. Harrison, K. Hughes, T. Jones, D. Leclère, A. J. Lynch, P. Leonard, M. E. McClain, D. Muruven, J. D. Olden, S. J. Ormerod, J. Robinson, R. E. Tharme, M. Thieme, K. Tockner, M. Wright, \& L. Young, 2020. Bending the Curve of Global Freshwater Biodiversity Loss: An Emergency Recovery Plan. BioScience 70: 330-342.

Tufts, B. L., J. Holden, \& M. DeMille, 2015. Benefits arising from sustainable use of North America's 
fishery resources: economic and conservation impacts of recreational angling. International Journal of Environmental Studies Routledge 72: 850-868, http://dx.doi.org/10.1080/00207233.2015.1022987.

Underwood, A. J., 1992. Beyond BACl: the detection of environmental impacts on populations in the real, but variable, world. Journal of Experimental Marine Biology and Ecology 161: 145-178, papers2://publication/uuid/58D141EA-0260-4014-99B7-D63A470D2A46.

Van Diggelen, R., A. P. Grootjans, \& J. A. Harris, 2001. Ecological restoration: State of the art or state of the science?. Restoration Ecology 9: 115-118.

Vitousek, P. M., H. A. Mooney, J. Lubchenco, \& J. M. Melillo, 1997. Human Domination of Earth's Ecosystems. Science 277: 494-499.

Wiegmann, D. D., \& J. R. Baylis, 1995. Male body size and paternal behaviour in smallmouth bass, Micropterus dolomieui (Pisces: Centrarchidae). Animal Behaviour 50: 1543-1555.

Wortley, L., J. M. Hero, \& M. Howes, 2013. Evaluating ecological restoration success: A review of the literature. Restoration Ecology 21: 537-543.

WWF, 2016. Living Planet Report 2016: Risk and resilience in a new era. WWF International. , http://awsassets.panda.org/downloads/lpr_2016_full_report_low_res.pdf.

Young, M. K., W. A. Hubert, \& T. A. Wesche, 1991. Selection of Measures of Substrate Composition to Estimate Survival to Emergence of Salmonids and to Detect Changes in Stream Substrates. North American Journal of Fisheries Management 11: 339-346. 